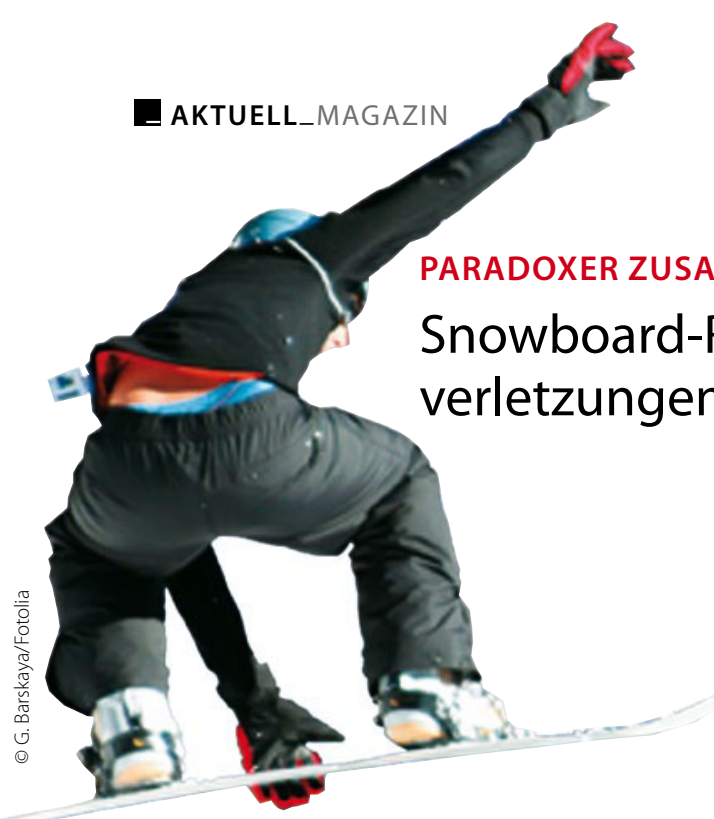

- Beim Snowboarden ist die Gefahr schwerer Schädeltraumen gerade für Anfänger, die auf flachen Pisten üben, relativ hoch. Dies zeigt eine Studie japanischer Neurochirurgen, die Unfalldaten von 959 Snowboard-Anfängern und 1408 Fortgeschrittenen analysiert haben.

70\% der Anfänger (Gruppe B) waren auf flachen oder mittleren Steigungen gestürzt, die Fortgeschrittenen (Gruppe A) hatten sich vornehmlich bei Sprüngen verletzt (48\%). In beiden Gruppen lagen okzipitale Läsionen vorn (56,2\% bzw. 43,9\%). Operativ versorgt werden mussten zehn Patienten der B-Gruppe $(1,04 \%)$, vier von ihnen trugen eine leichte Behinderung davon, für zwei endete das Snowboard-Abenteuer im Koma, zwei weitere starben. Unter den besseren Fahrern landeten fünf im OP

$(0,36 \%)$, zwei waren danach leicht, einer schwer behindert, einer starb.

Besonders auffällig: Die Anfänger erlitten deutlich mehr subdurale Hämatome, was die Autoren so erklärten: Wer noch keine Erfahrung im Snowboarden hat, kann nicht adäquat auf das „Opposite-Edge“-Phänomen reagieren. Dabei kann es gerade auf flachen Hängen zu einer schnellen Rotation des Bretts nach hinten kommen; der ungeübte Fahrer fällt auf den Hinterkopf. Aufgrund der Rotationskräfte bildet sich im Kopf des Snowboarders ein Spalt zwischen Hirnparenchym und Schädeldecke; dadurch werden verbindende Gefäße geschädigt, was zur Einblutung führt.

$\mathrm{EO}$ -

Koyama S et al. Am J Sport Med 2011, published online Sept. 29, doi:10.1177/0363546511422331

\title{
Ein Volk von Hautkranken?
}

- Bei mehr als einem Viertel der Deutschen besteht dermatologischer Handlungsbedarf.

In einer epidemiologischen Querschnittstudie griffen Prof. Matthias Augustin von der Universität Hamburg und sein Team auf Daten von 90880 Angestellten zwischen 16 und 70 Jahren zurück, die sich zwischen 2004 und 2009 einem Hautkrebsscreening unterzogen hatten. Bei einem Viertel der Probanden $(25,1 \%)$ wurden Nävuszellnävi und bei $21,1 \%$ papillomatöse Nävi diagnostiziert. Auch entzündliche Hauterkrankungen waren zahlreich vertreten: Vor allem Akne vulgaris (3,9\%), Psoriasis $(2,0 \%)$, Rosacea $(2,3 \%)$ und das atopische Ekzem (1,3\%). Bei 11,2\% der Teilnehmer wurden Pilzinfektionen, vorwiegend Nagel- und Fußpilz, festgestellt. Männer waren deutlich häufiger betroffen als Frauen (15,4\% vs. 6,5\%).

Die Hautärzte stuften die Hautbefunde von 11291 Probanden als behandlungsbedürftig ein. Auch hier schnitten die Männer deutlich schlechter ab als die Frauen (behandlungsbedürftig: $30,7 \%$ vs. $22,2 \%$ ). Einen besonders schlechten Hautzustand hatten über 60-jährige Männern. Fast die Hälfte (44,8\%) aus dieser Altersgruppe war therapiebedürftig.

BJD 2011, 165: 865-873

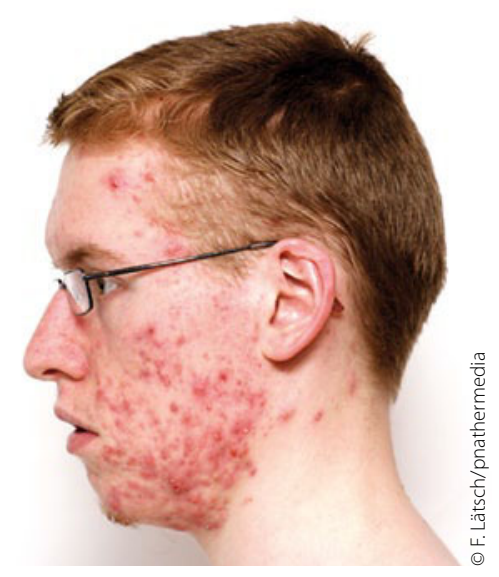

Schlechter Hautzustand nicht nur bei jungen Aknepatienten. 